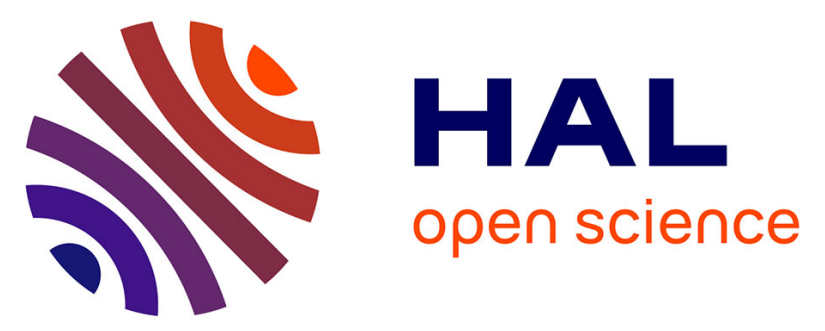

\title{
Pulse analysis and electric contact measurements in spark plasma sintering
}

Charles Manière, Anthony Pavia, Lise Durand, Geoffroy Chevallier, Vincent Bley, Khalid Afanga, Alain Peigney, Claude Estournès

\section{To cite this version:}

Charles Manière, Anthony Pavia, Lise Durand, Geoffroy Chevallier, Vincent Bley, et al.. Pulse analysis and electric contact measurements in spark plasma sintering. Electric Power Systems Research, 2015, vol. 127, pp. 307-313. 10.1016/j.epsr.2015.06.009 . hal-01493438

\section{HAL Id: hal-01493438 \\ https://hal.science/hal-01493438}

Submitted on 21 Mar 2017

HAL is a multi-disciplinary open access archive for the deposit and dissemination of scientific research documents, whether they are published or not. The documents may come from teaching and research institutions in France or abroad, or from public or private research centers.
L'archive ouverte pluridisciplinaire HAL, est destinée au dépôt et à la diffusion de documents scientifiques de niveau recherche, publiés ou non, émanant des établissements d'enseignement et de recherche français ou étrangers, des laboratoires publics ou privés. 


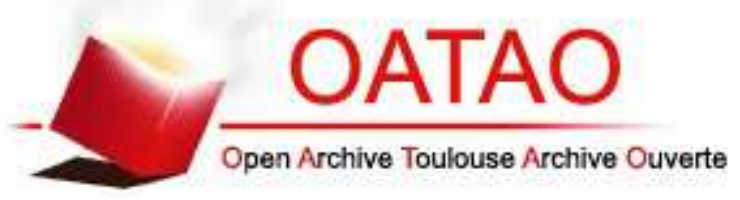

\section{Open Archive TOULOUSE Archive Ouverte (OATAO)}

OATAO is an open access repository that collects the work of Toulouse researchers and makes it freely available over the web where possible.

This is an author-deposited version published in : http://oatao.univ-toulouse.fr/ Eprints ID : 16781

To link to this article : DOI:10.1016/j.epsr.2015.06.009

URL : http://dx.doi.org/10.1016/j.epsr.2015.06.009

To cite this version : Manière, Charles and Pavia, Anthony and Durand, Lise and Chevallier, Geoffroy and Bley, Vincent and Afanga, Khalid and Peigney, Alain and Estournès, Claude Pulse analysis and electric contact measurements in spark plasma sintering. (2015) Electric Power Systems Research, vol. 127. pp. 307-313. ISSN 0378-7796

Any correspondence concerning this service should be sent to the repository administrator: staff-oatao@ listes-diff.inp-toulouse.fr 


\title{
Pulse analysis and electric contact measurements in spark plasma sintering
}

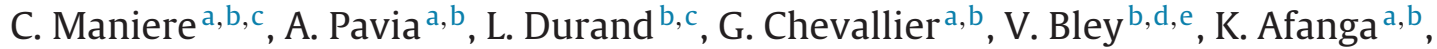 \\ A. Peigney ${ }^{a, b}, C$. Estournès ${ }^{a, b, *}$ \\ ${ }^{a}$ CNRS, Institut Carnot CIRIMAT, Toulouse, France \\ b Université Paul Sabatier, 118 route de Narbonne 31062 Toulouse, France \\ ' CNRS-CEMES (Centre d'Elaboration de Matériaux et d'Etudes Structurales), 29 Rue Jeanne Marvig, 31055 Toulouse, France \\ d Université de Toulouse, UPS, INPT, LAPLACE, 118 route de Narbonne - Bât. 3R3, F-31062 Toulouse cedex 9, France \\ e CNRS, LAPLACE, F-31062 Toulouse, France
}

Keywords:

Spark plasma sintering

Current pulses

Joule heating

Electrical contact

Papyex $^{\circledR}$

Experimental design

\begin{abstract}
A B S T R A C T
In order to model the current density distribution and the temperature changes of the tools used during a spark-plasma-sintering (SPS) cycle, the variation of the power delivered by an SPS machine and the graphite-Papyex ${ }^{\circledR}$-graphite electrical contacts were studied experimentally. The electric device was also characterized; in particular current pulse characteristics and their behavior with time were studied in various conditions of temperature, pulses sequences, materials and total electric power dissipated. It is well known that the performance of an electric contact is dependent on the applied pressure and the temperature. First, by varying the pressure during the SPS cycle the effect of the electric contacts is clearly seen. Secondly, in order to determine the behavior of such contacts experimentally over a pressure range of 10-50 MPa and temperatures of $50-800^{\circ} \mathrm{C}$, a Dœhlert experimental design was used.
\end{abstract}

\section{Introduction}

The spark-plasma-sintering (SPS) process is used to manufacture complex shaped solid materials from powder. The interesting part of the process is its ability to sinter in a few minutes while maintaining a fine microstructure in the refractory materials compared to hours with high pressure sintering and several tens of hours with natural sintering. This performance is due to the simultaneous application of high uniaxial pressure and temperature by Joule heating via pulsed current passing through the tools and also the material to be sintered if it conducts electricity. Moreover, the SPS method heats the part being made very quickly compared to the high-pressure method.

The aim of electro-thermal modeling this process was to predict the thermal gradients in the sample and to explain their effects on the final microstructure [1-3]. In the literature, most modeling is performed using the finite elements method (FEM). In FEM modeling authors often consider that all the contacts are perfect.

\footnotetext{
* Corresponding author at: CIRIMAT, 118 route de Narbonne, 31062 Toulouse, France. Tel.: +33 561556109; fax: +33 561556163.

E-mail address: estournes@chimie.ups-tlse.fr (C. Estournès).
}

However, recent works, in particular that of Pavia [4], where a rapid infrared camera was used to observe an open die during a whole SPS cycle, revealed that heat transfer at the Punch/Die interface has a predominant effect on the thermal-gradient particularly when insulating materials are sintered [4]. Usually, in SPS tools, a graphite sheet (Papyex ${ }^{\circledR}$ from Mersen Co., Gennevilliers, France) is introduced between the punch, the inner die wall and the sample to ensure easy sample removal, with a low friction coefficient and good thermal contact between the parts.

The contact phenomena and electric and thermal effects are typically dependent not only on the applied pressure but also on the temperature [5-8]. They are explained by the non-ideal surface due to the roughness of the materials involved in the contact [9].

The challenge of our present study was to evaluate these electrical contact resistances (ECR) essential in FEM modeling of the SPS process. There are already some works published on the determination of the electric contact between the parts of the SPS tools. Anselmi-Tamburini et al. [10] determined, by ambient electric resistance measurements, the pressure dependence of the electric contact in alumina and copper samples and concluded that above a uniaxial applied pressure of $50 \mathrm{MPa}$, it is useless to consider any contact phenomena in the vicinity of the sample. But they do draw our attention to the contact between the punches and the die which 


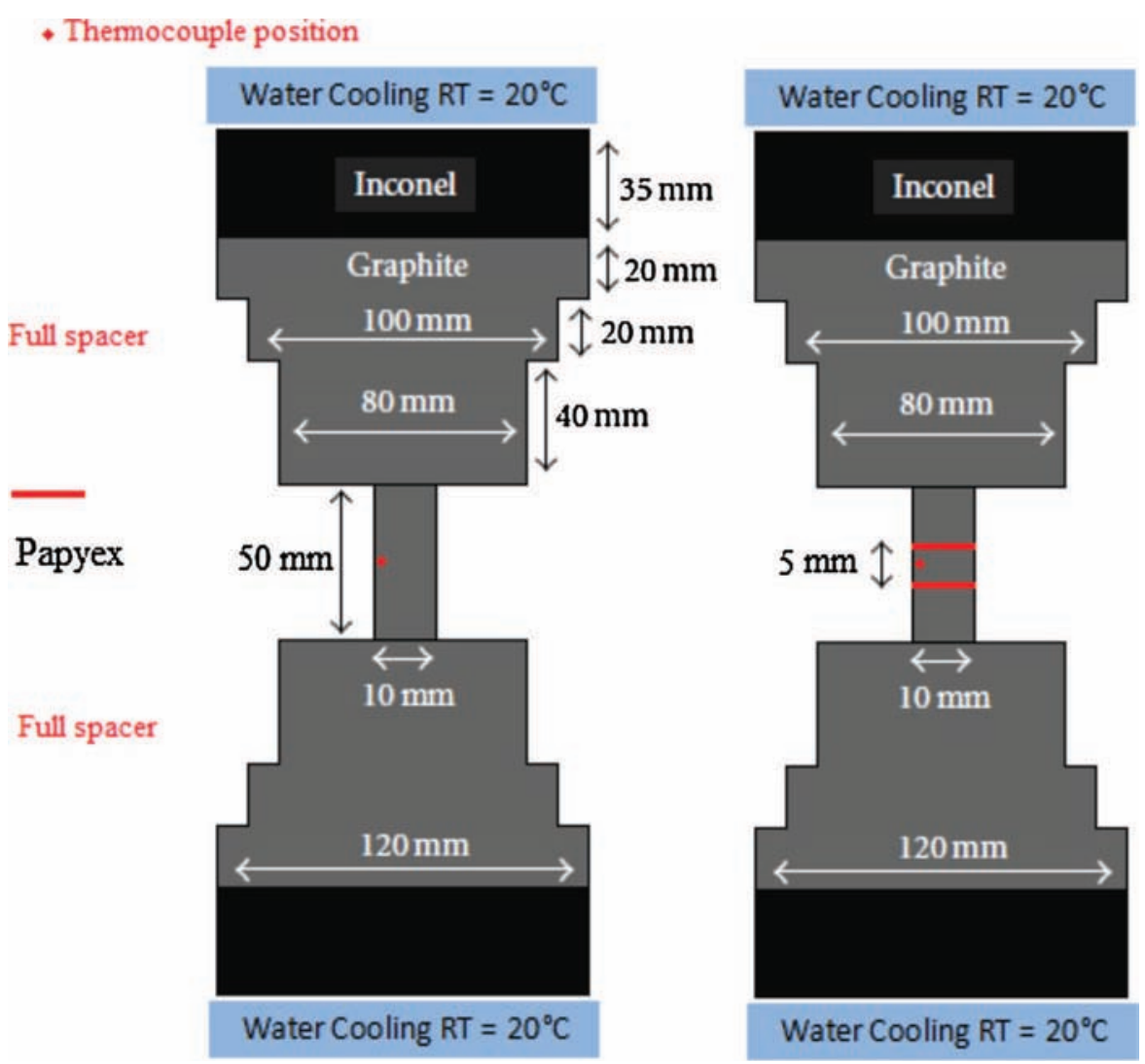

Fig. 1. Representation of the two set-ups: with and without contacts $[1,2]$. (For interpretation of the references to color in this figure citation in text, the reader is referred to the web version of this article.)

is assumed to play a stronger role than the global resistance of the tool. Vanmeensel et al. and McWilliam et al. [11,12] made similar studies of the electric contact. They measured the electric resistances of different SPS configurations with and without contacts. The non-contact configuration is used to subtract all resistances except the electrical contact resistance in the contact configuration. This process is explained below in Eq. (IV) used to measure contact resistance.

In the present study, we chose the same strategy asking them to determine the electric resistances of the graphite/Papyex ${ }^{\circledR} /$ graphite contact to follow the behavior of the contact with temperature and pressure. Indeed previous studies mainly considered the pressure dependence of the ECR. Here, a Dœhlert experimental design was used.

\section{Experimental}

The experiment was carried out on the SPS machine (Dr. Sinter 2080, SPS Syntex Inc, Japan) at the "Plateforme Nationale CNRS de Frittage Flash" located at University Toulouse III-Paul Sabatier.

The first part of this paper is devoted to the analysis of the DC pulsed current given by the device used considering two types of materials to be sintered respectively more conducting (manganese) and insulating (alumina) compared to the graphite used for the tools (Ref. 2333 from Mersen Co., Gennevilliers, France). The molds used have either 8 or $36 \mathrm{~mm}$ inner diameters. Sensors were selected for sampling the signals $(u(t)$ across the column and $i(t)$ passing through) with a sufficiently high frequency (up to $10,000 \mathrm{~Hz}$ ) to describe each pulse correctly. For the instantaneous current a wide band Rogowski coil sensor (Power Electronic Measurements, CWT60) was used. To measure the voltage across the SPS column, the potential was considered uniform over the entire contact surface. From the synchronized voltage and intensity measurements, average and RMS values ( $U_{\mathrm{ave}}, U_{\mathrm{rms}}, I_{\mathrm{ave}}$ and $\left.I_{\mathrm{rms}}\right)$ were calculated using a Labview routine (National Instrument software). The signal was also calibrated using an oscilloscope to verify the correspondence between measured and calculated mean values.

The second part of this paper is devoted to highlighting the importance of electric contacts in SPS tools. In particular, the electric contacts graphite/Papyex/graphite present mainly at the inner interfaces of the mold are determined using the principle described by Vanmeensel et al. [11]. Two SPS central punch configurations were studied. One with two graphite/Papyex ${ }^{\circledR} /$ graphite contacts (in red in Fig. 1) and one without contacts. The height of this part of the columns is the same in both configurations. The electric resistance was obtained for each of the two set-ups using the current and voltage values given by the SPS machine.

\section{Results and discussions}

\subsection{Study of machine current}

To know what kind of current value is given by the display of the SPS machine, the Rogowski coil was placed below the SPS chamber at the output of the current. The measurements reported in Fig. 2 show that the value of current given by the machine $\left(I_{\mathrm{sps}}\right)$ roughly corresponds to the average current calculated by the Rogowski coil ( $\left.I_{\text {ave }}\right)$.

For thermal effect studies, it would be better to use the rms rather than the average values. The coefficient usually used to convert the average into rms values for theoretical rectified pulsed current, either $U$ or $I$, is simple and near 1.11 [13]. In any case, as the electrical resistance is the ratio of the voltage to the current intensity, we should use either the average or the rms values. 


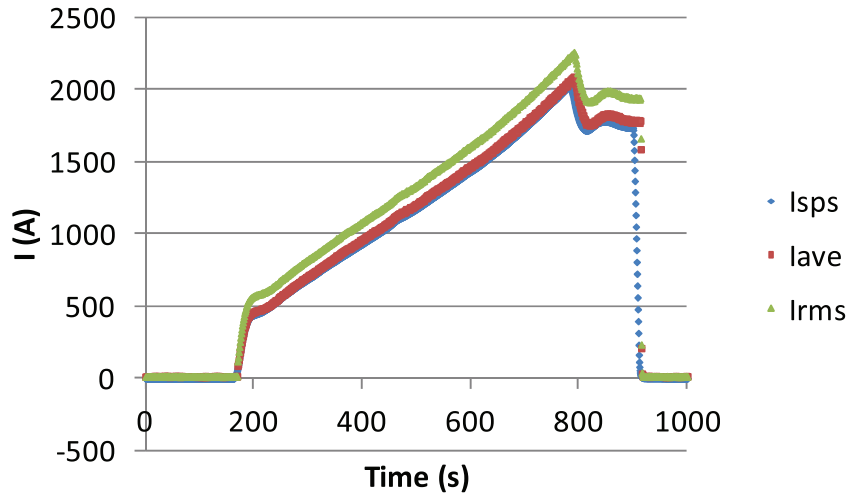

Fig. 2. Comparison of the different current measurements.

\subsection{Study of pulsed current sequences}

The Rogowski coil sensor allowed us to follow the intensity and shape of the current pulses for various sequences and during the whole SPS cycle. This required an $8 \mathrm{~mm}$ inner diameter graphite die containing either a conducting or insulating powdered material (i.e. manganese or alumina see Table 1$)$. Three types of sequences ( $X$ is the number of pulses and $Y$ the number of dead times; i.e. $X-Y=12-$ $2,9-5,7-7$ ) were tested at various temperatures between 200 and $1000^{\circ} \mathrm{C}$ and for an applied pressure of $100 \mathrm{MPa}$. It was found (Fig. 3) that for these three sequences, the actual number of pulses was maintained compared to the number asked for although Chen et al. [14] have shown that this is not the case for sequences with small numbers of pulses. In agreement with these authors, it is shown here that a reduction in the number of pulses at a given temperature
Table 1

Electrical resistivity of various sample materials depending on the absolute temperature $T[1 ; 2]$.

\begin{tabular}{ll}
\hline Material & Electrical resistivity $(\Omega \mathrm{m})$ \\
\hline Manganese & $1.43 \times 10^{-6}+4.0 \times 10^{-10} \mathrm{~T}-3 \times 10^{-13} \mathrm{~T}^{2}$ \\
Alumina & $8.7 \times 10^{19} \mathrm{~T}^{-4.82}$ \\
Graphite & $2.14 \times 10^{-5}-1.34 \times 10^{-8} \mathrm{~T}+4.42 \times 10^{-12} \mathrm{~T}^{2}$ \\
\hline
\end{tabular}

implies a higher maximum intensity. The intensity of the pulses is also increased when temperature is increased. This effect is shown in Fig. 3(g)-(i) where $I_{\max }$ is plotted versus temperature for various sequences for both alumina and manganese powders. Note that there is not too much difference in the values of $I_{\max }$ irrespective of the type material studied.

\subsection{Study of the pulse intensity}

Comparison of the pulse patterns acquired at different temperatures for a 12-2 sequence allowed us to study the durations of the pulses and the dead times. Pulse duration increased with temperature and hence with the current intensity (Fig. 4a). In contrast, the dead time decreased with increasing temperature and intensity (Fig. 4b) while the global period of the signal remained unchanged whatever the temperature. This was observed for an $8 \mathrm{~mm}$ inner diameter die configuration with either an alumina or a manganese sample, a configuration that does not require elevated electric power to heat the tools. It was also observed on increasing the power demand that, for an $8 \mathrm{~mm}$ die, when $I_{\max }$ was near and above $1000 \mathrm{~A}$, the signal no longer returned to zero between two successive pulses. Mc Williams et al. [12] have shown that increasing the volume of the die implies increasing the electric
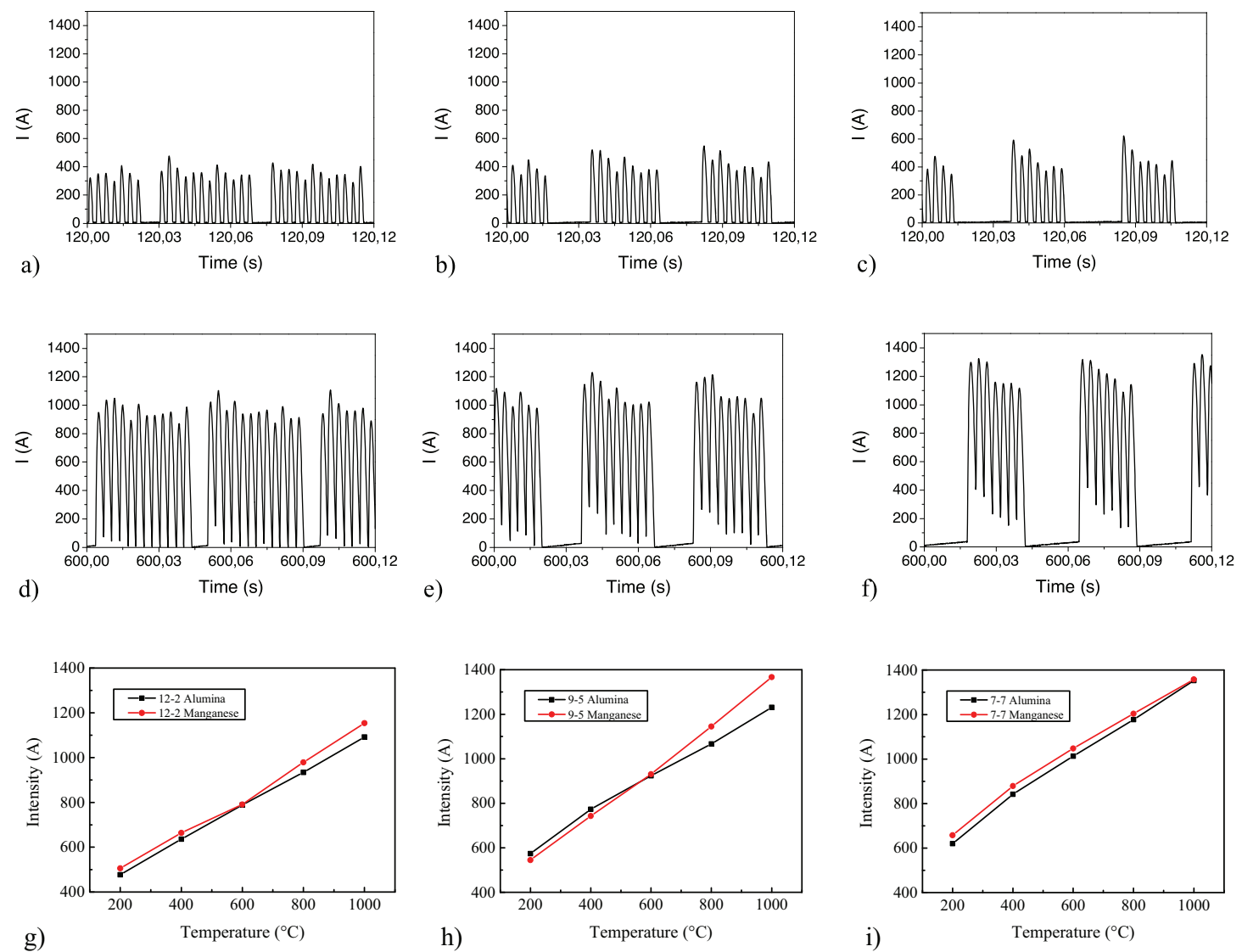

Fig. 3. Record of the current pulse intensity at different temperatures and pulses sequences, ((a)-(c)) $200{ }^{\circ} \mathrm{C}$, ((d)-(f)) $1000{ }^{\circ} \mathrm{C}$, (a, b) $12-2$, (b, e) $9-5$, (c, f) $7-7$, (g-i) $I_{\text {max }}$ measured in various pulse sequences and temperatures. 

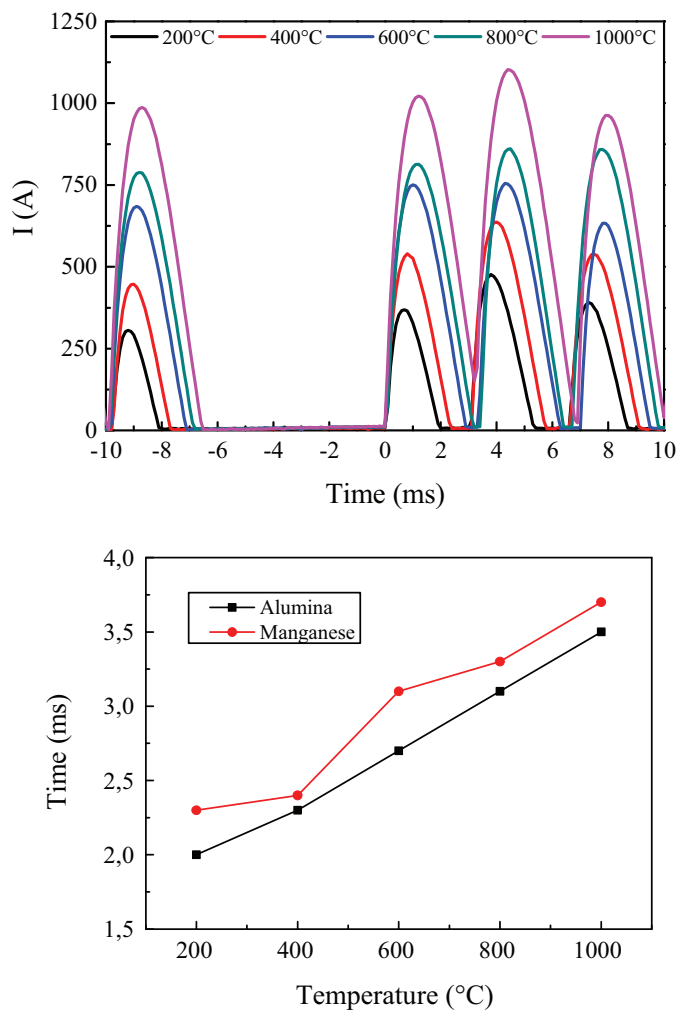

Fig. 4. Study of pulse time step: (a) pulse form at different temperatures; (b) pulse time versus temperature.

power necessary to attain the same temperature in the same configuration. This implies that the phenomenon previously observed (Fig. 4) is amplified for a $36 \mathrm{~mm}$ die which increases the graphite volume and the electric power needed to heat the assembly. Consequently the resulting signal is no longer simply pulsed but looks like a square wave (see Fig. 5).

\subsection{Electrical resistance of the column}

The RMS value of the current ( $\left.I_{\mathrm{rms}}\right)$ was obtained using a Rogowski coil sensor and the RMS voltage $\left(V_{\text {rms }}\right)$ using two electrodes located between the largest spacers and the Inconel ram cover. The global electrical resistance of the SPS column can thus be obtained by calculating the ratio $U_{\mathrm{rms}} / I_{\mathrm{rms}}$. Fig. 6 represents the variation of the electrical resistance of the column $\left(R_{\text {calc }}=U_{\text {rms }} / I_{\text {rms }}\right)$ versus time in two SPS cycles. The first is obtained with a pressure of $5 \mathrm{MPa}$ throughout the cycle while the second at $100 \mathrm{MPa}$ was applied before the beginning of the increase in temperature with a heating rate of $100^{\circ} \mathrm{C} / \mathrm{min}$ up to $1000^{\circ} \mathrm{C}$ and $4 \mathrm{~min}$ of dwell.

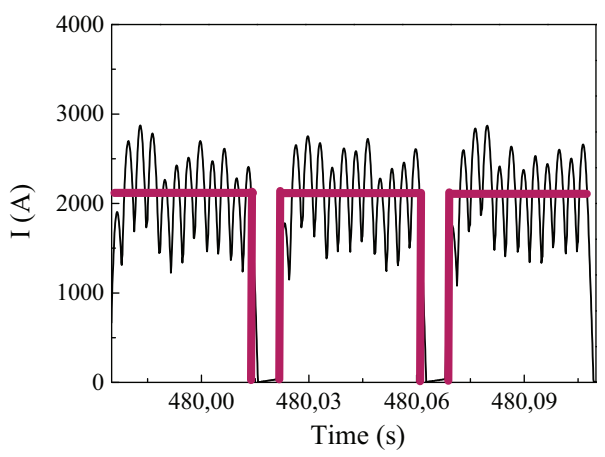

Fig. 5. Current pulse shape at high intensity.

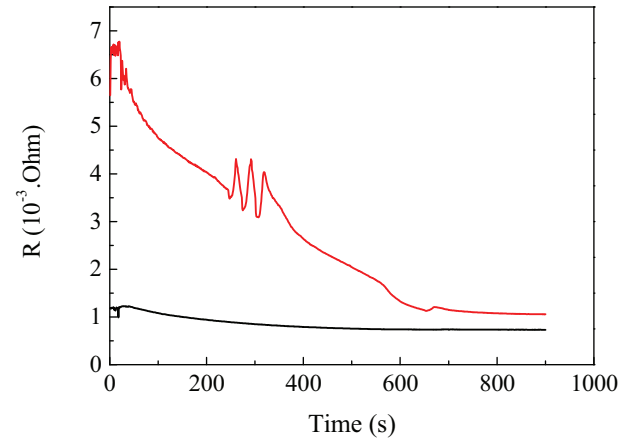

Fig. 6. Electric resistance of the column with a uniaxial pressure of $5 \mathrm{MPa}$ (red) or $100 \mathrm{MPa}$ (black). (For interpretation of the references to color in this figure legend, the reader is referred to the web version of this article.)

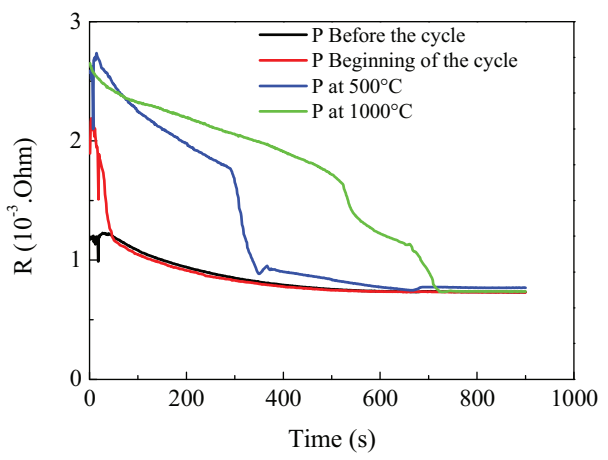

Fig. 7. Electrical column resistance in various pressure cycles.

The resistance calculated for the cycle at $5 \mathrm{MPa}$ was significantly higher than that obtained for a pressure of $100 \mathrm{MPa}$, which is probably due to the difference in electrical contact resistances (ECR) at the column interfaces. With the thermal expansion of the graphite parts during the SPS cycle, the pressure increases with temperature and consequently the ECR and the global resistance of the column decrease, which is clearly seen for the low uniaxial pressure (red curve in Fig. 6), the instability at 300 s corresponding to the shrinkage zone due to the sintering. By varying the time at which the load of $100 \mathrm{MPa}$ is applied (Fig. 7), the resistance was seen to be higher before pressure application but tended to converge to the same value at the end of the cycle. This clearly shows the correlation between the pressure and the ECR: an increase of the uniaxial pressure results in a decrease of the ECR.

\subsection{Method of ECR determination}

In the configurations in Fig. 1, all the electrical resistances are in series. Therefore, the electrical contact resistance graphite/Papyex ${ }^{\circledR} /$ graphite $\left(R_{\mathrm{C}}\right)$ can be determined by removing the value of total electrical resistance of the column without contact $\left(R_{\mathrm{tot}}\right)$ from that with contact $\left(R_{\mathrm{totc}}\right)$, at a given dwell temperature.

As in the equivalent schemes presented in Fig. 8, where $R_{\mathrm{C}}$ is the contact resistance and $R_{\mathrm{a}}+R_{\mathrm{b}}$ is the sum of all other resistances present in the system ( $R_{\mathrm{a}}$ the upper part and $R_{\mathrm{b}}$ the lower part):

$R_{\text {totc }}$, and $R_{\text {tot }}$, the sum of all series resistances, respectively with and without the central graphite/Papyex ${ }^{\circledR}$ /graphite contacts, from the ratio voltage $(U) /$ intensity $(I)$.

$$
\begin{aligned}
& R_{\text {totc }}=R_{\mathrm{a}}+R_{\mathrm{c}}+R_{\mathrm{b}}=\frac{U_{\mathrm{c}}}{I_{\mathrm{c}}} \\
& R_{\mathrm{tot}}=R_{\mathrm{a}}+R_{\mathrm{b}}=\frac{U_{\mathrm{b}}}{I_{\mathrm{b}}}
\end{aligned}
$$




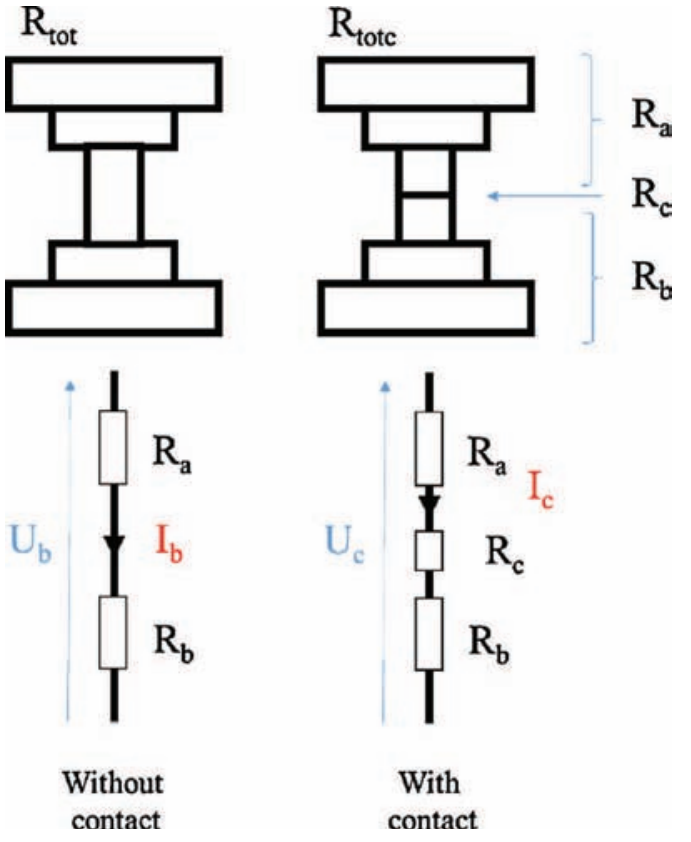

Fig. 8. Electrical equivalent model.

By replacing $R_{\mathrm{a}}+R_{\mathrm{b}}$ in (I) we obtain:

$R_{\text {totc }}=R_{\text {tot }}+R_{\mathrm{c}}$

$R_{\mathrm{c}}=R_{\mathrm{totc}}-R_{\mathrm{tot}}=\frac{U_{\mathrm{c}}}{I_{\mathrm{c}}}-\frac{U_{\mathrm{b}}}{I_{\mathrm{b}}}$

The values $U_{\mathrm{c}}, U_{\mathrm{b}}, I_{\mathrm{c}}$ and $I_{\mathrm{b}}$ are average values given by the SPS machine and were determined in the stationary state (dwell temperature).

To determine the behavior of the ECR with the applied pressure and temperature an experimental design was used. To solve this problem it is possible to use either Taguchi, Dœhlert or composite experimental design approach. Dœhlert's approach was preferred because it gives us and future authors the possibility to easily move the experimental domain to higher pressures and temperatures with a minimum of three more SPS experiments.

The different experiments in Fig. 9 were carried out applying the Dœhlert experimental design $[15,16]$. With this method, the choice of study range is crucial. Indeed this type of experimental design is based on the general principle of interpolation of experimental results by a second degree polynomial function. Therefore, if the range of study is too high there is a risk of having an interpolation function that is not suitable to describe or fit the experimental data points. On the other hand, doing the interpolation over too short a range will not be representative. The range of applied pressures was

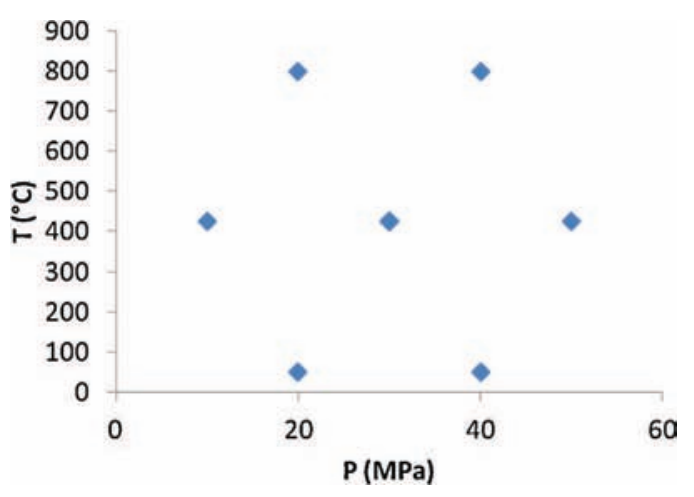

Fig. 9. Dœhlert experiments.
Table 2

(a) The table of experiments and (b) coefficients of the model.

\begin{tabular}{lll}
\hline $\begin{array}{l}\text { (a) } \\
\text { Pressure (MPa) }\end{array}$ & Temperature $\left({ }^{\circ} \mathrm{C}\right)$ & ECR $(\Omega)$ \\
\hline 30 & 425 & $1.07 \mathrm{E}-03$ \\
30 & 425 & $1.03 \mathrm{E}-03$ \\
50 & 425 & $8.99 \mathrm{E}-04$ \\
40 & 800 & $4.50 \mathrm{E}-04$ \\
20 & 800 & $4.04 \mathrm{E}-04$ \\
10 & 425 & $9.67 \mathrm{E}-04$ \\
20 & 50 & $3.51 \mathrm{E}-03$ \\
40 & 50 & $2.15 \mathrm{E}-03$ \\
& & \\
$(\mathrm{~b})$ & & \\
& & $+/-$ \\
$a_{0}$ & Coefficients & $3.59 \mathrm{E}-04$ \\
$P\left(\mathrm{a}_{1}\right)$ & $1.05 \mathrm{E}-03$ & $2.93 \mathrm{E}-04$ \\
$T\left(\mathrm{a}_{2}\right)$ & $-2.41 \mathrm{E}-04$ & $2.93 \mathrm{E}-04$ \\
$P T\left(\mathrm{a}_{12}\right)$ & $-1.39 \mathrm{E}-03$ & $5.86 \mathrm{E}-04$ \\
$P^{2}\left(\mathrm{a}_{11}\right)$ & $8.11 \mathrm{E}-04$ & $5.08 \mathrm{E}-04$ \\
$\mathrm{~T}^{2}\left(\mathrm{a}_{22}\right)$ & $-1.19 \mathrm{E}-04$ & $5.08 \mathrm{E}-04$ \\
\hline
\end{tabular}

chosen here between 10 and $50 \mathrm{MPa}$. Indeed, in this configuration (diameter of the part $=10 \mathrm{~mm}$ ) the low threshold load leading to a stable value that takes into account the dilation of the stack, corresponds to a minimum applied pressure of $10 \mathrm{MPa}$. As reported by Anselmi-Tamburini et al., it is useless to go above $50 \mathrm{MPa}$ because the contact tends to be perfect over this high threshold. The temperature range is limited from 50 up to $800^{\circ} \mathrm{C}$ in order to limit the interpolation problem (see above).

The polynomial second degree model is:

$y=a_{0}+a_{1} x_{1}+a_{2} x_{2}+a_{12} x_{1} x_{2}+a_{11} x_{1}^{2}+a_{22} x_{2}^{2}$

Where, $a_{i}$ are the effect coefficients of pressure, temperature, the interaction between pressure and temperature, and the second degree effects on the pressure and temperature, $y$ the response here it is the electrical contact resistance, $x_{1}$ is the pressure and $x_{2}$ the temperature.

\subsection{ECR experimental design}

The present model has a correlation coefficient $\left(R^{2}\right)$ of 0.97 , i.e. near 1 , the interpolation function of the results is therefore correct. The experimental table to determine the electrical contact resistances (ECR) of a $10 \mathrm{~mm}$ diameter punch is represented in Table $2 \mathrm{a}$. The coefficients of the model and their standard deviation $(+/-)$ are reported in Table $2 \mathrm{~b}$. The comparison of the coefficients in Fig. 10 shows a predominant effect of temperature (the $a_{2}$ coefficient is the highest and is negative which tells us that the temperature decreases the electrical contact) and that there is a significant pressure/temperature interaction $\left(a_{12}\right)$. The positive second degree coefficient $a_{12}$ shows that the increases of pressure and temperature have a positive curvature.

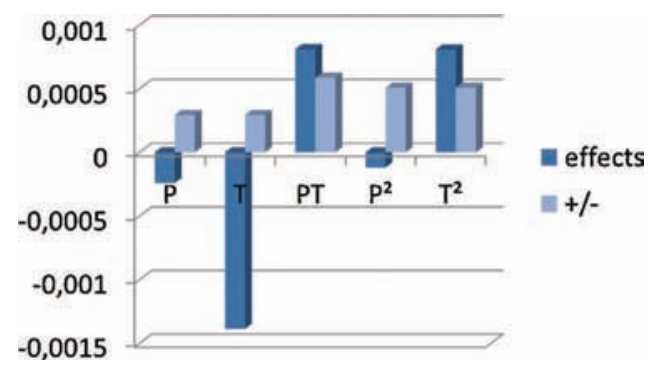

Fig. 10. Representation of each value of the coefficients and their standard deviations. 
a)

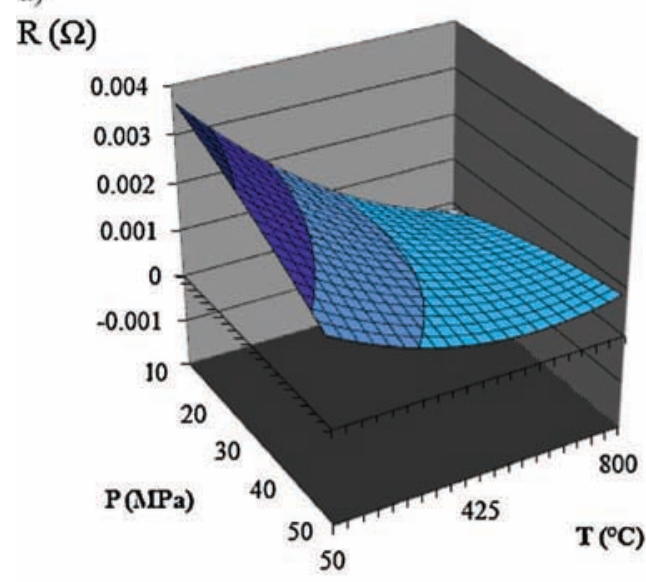

b)

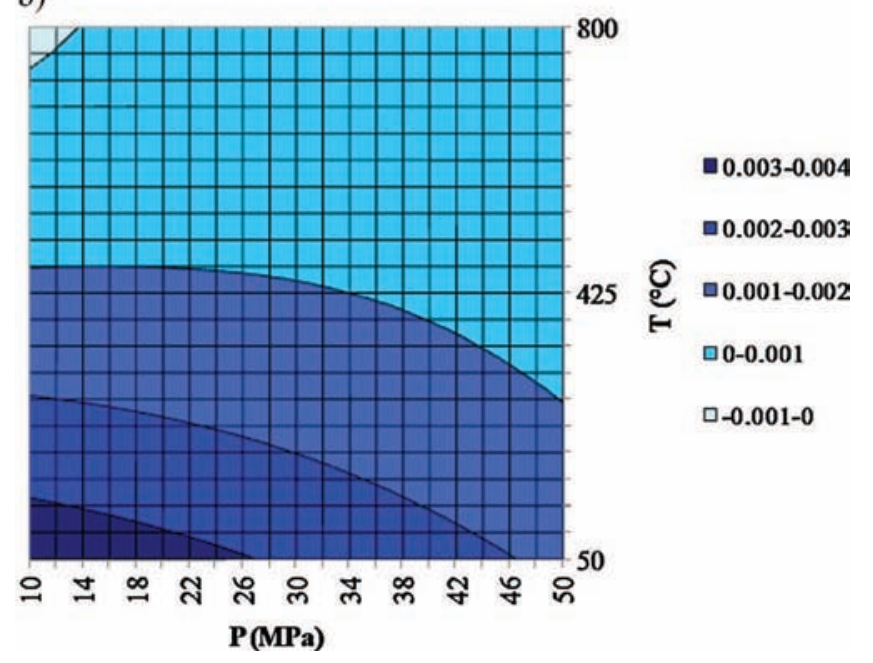

Fig. 11. Electrical contact resistance versus pressure and temperature (a) 3D representation (b) 2D projection.

Fig. 11a is a 3D graph of the interpolation fonction of the ECR in $\Omega$ and Fig. 11b the projection in 2D. These figures show that, as expected, the ECR decreases with applied pressure and temperature and reaches a value near zero at high temperatures and pressures. Moreover, the function seems to be asymptotic with an increase of temperature and presure at roughly $800^{\circ} \mathrm{C}$ and $50 \mathrm{MPa}$ probably due to the positive interraction coefficient ( $a_{12}$ or PT). In most SPS cycles, in particular for sintering of ceramics, the experimental conditions are such that the values of $800^{\circ} \mathrm{C}$ and $50 \mathrm{MPa}$ are exceeded. Hence it is perfectly accepted that the ECR value can be ignored around the sample where the presure and temperature are maximum (higher than $50 \mathrm{MPa}$ and $800^{\circ} \mathrm{C}$ ). However, for the friction zone where the contact between punches/Papyex ${ }^{\circledR}$ inner wall of the die is moving, the pressure is very low and is not in the pressure range of this experimental design requiring determination using a different approach.

The equation of model $(\mathrm{V})$ is expressed in centered and reduced variables with maximum and minimum equal to 1 and -1 . These variables are used in experimental design to be able to compare the effects of each of the experimental parameters (such as $P$ and $T$ in Fig. 10). To rewrite Eq. (V) in a form that can be easily included in electro-thermal medialization, the $\operatorname{ECR}\left(\Omega \mathrm{m}^{2}\right)$ can be expressed as a function of the pressure $P(\mathrm{~Pa})$ and the temperature $T(\mathrm{~K})$ :

$$
\begin{aligned}
\mathrm{ECR}= & 5.85 * 10^{-7}-4.68 * 10^{-15} P-9.45 * 10^{-10} T \\
& +7.36 * 10^{-18} P T-2.33 * 10^{-23} P^{2}+3.39 * 10^{-13} T^{2}
\end{aligned}
$$

The ECR values obtained in the present study are about $3 \times 10^{-7}$ $\left(\Omega \mathrm{m}^{2}\right)$ at low pressure and temperature and of the order of $7 \times 10^{-8}$ $\left(\Omega \mathrm{m}^{2}\right)$ at high pressure and temperature. These values are of the same order magnitude as those obtained, for other graphite references, by Zavaliangaos [5] and Maizza et al. [8] who obtained ECR values of $1.3 \times 10^{-7}\left(\Omega \mathrm{m}^{2}\right)$ on the vertical contact (low pressure) and $8 \times 10^{-8}\left(\Omega \mathrm{m}^{2}\right)$ on the horizontal contact (high pressure).

\section{Summary and conclusion}

The pulsed current of the Dr. Sinter 2080 SPS machine and the electric contact inside the SPS tools have been studied.

The current pulses showed that the increase in temperature is obtained by increasing the maximum intensity of the pulse while respecting the desired pulse pattern.

The increase of the maximum intensity of the pulses goes with an increase of their step time and a decrease of the dead time. Moreover, the pulse current representation at high electric power has shown that the after roughly $3000 \mathrm{~A}$ of maximum intensity the shape of the current corresponds to a square wave.

Measurements of the electrical resistance of the column show that ECR exists and decreases with both pressure and temperature.

The experimental design helped us to understand how the electric contact resistance (ECR) works with pressure and temperature by the following points:

- ECR decreases with pressure and temperature.

- ECR decreases asymptotically to zero near $800^{\circ} \mathrm{C}$ and $50 \mathrm{MPa}$.

- The last point suggests that these ECR are negligible around the sample because the temperatures and pressures are higher in common cycles (as shown by Anselmi et al. [10]).

The electric contacts between the punches and the die are in a place of very low pressure (lower than $10 \mathrm{MPa}$ ) and are expected to have a stronger role.

\section{Acknowledgements}

The support of the LAPLACE for the instrumentation and fruitful discussions and the Plateforme Nationale CNRS de Frittage Flash (PNF2/CNRS) were gratefully appreciated. C.M and C.E. thank the French National Research Agency (ANR) for the financial support of this study within the project ANR09 MAPR-007 Impulsé.

\section{References}

[1] A. Pavia, L. Durand, F. Ajustron, V. Bley, G. Chevallier, A. Peigney, C. Estournes, Electro-thermal measurements and finite element method simulations of a spark plasma sintering device, J. Mater. Process. Technol. 213 (2013) 1327-1336.

[2] G. Molénat, L. Durand, J. Galy, A. Couret, Temperature control in spark plasma sintering: an FEM approach, J. Metall. 2010 (2010), Article ID 145431.

[3] Th. Voisin, L. Durand, N. Karnatak, S. Le Gallet, M. Thomas, Y. Le Berre, J.-F. Castagné, A. Couret, Temperature control during spark plasma sintering and application to up-scaling and complex shaping, J. Mater. Process. Technol. 213 (2013) 269-278.

[4] A. Pavia, Etude fondamentales pour la compréhension des mecanismes des matériaux par la technologie Spark Plasma Sintering (PhD Thesis), Université Toulouse III Paul Sabatier, 2012.

[5] A. Zavaliangaos, J.Zhang, M. Krammer, J.R. Groza, Temperature evolution during field activated sintering, Mater. Sci. Eng. A 379 (2004) 218-228.

[6] D. Tiwari, B. Basu, K. Biswas, Simulation of thermal and electric field evolution during spark plasma sintering, Ceram. Int. 35 (2009) 699-708.

[7] J. Zhang, Numerical simulation of thermoelectric phenomena in field activated sintering (Ph.D. thesis), Drexel University, Philadelphia, PA, 2004.

[8] G. Maizza, S. Grasso, Y. Sakka, Moving finite-element mesh model for aiding spark plasma sintering in current control mode of pure utrafine WC powder, J. Mater. Sci. 44 (2009) 1219-1236.

[9] R. Holm, Electric Contacts: Theory and Applications, 4th ed., Springer/Verlag Berlin, Heildelberg/New York, 1967. 
[10] U. Anselmi-Tamburini, S. Gennari, J.E. Garay, Z.A. Munir, Fundamental investigations on the spark plasma sintering/synthsis process. II. Modeling of current and temperature distributions, Mater. Sci. Eng. A 394 (2005) 139-148.

[11] K. Vanmeensel, A. Laptev, J. Vleugels, O. Van Der Biest, Modelling of the temperature distribution during field assisted sintering, Acta Mater. 53 (2005) 4379-4388.

[12] B.A. McWilliams, Numerical simulation of electric field assisted sintering (Ph.D. thesis), Drexel University, Philadelphia, PA, 2008.

[13] R. Mercier, H. Sauvignet, R1015, 1986, http://www.techniques-ingenieur.fr/ res/pdf/encyclopedia/tiare-r1015-version1.pdf
[14] U. Chen, U. Anselmi-Tamburini, J.E. Garay, J.R. Groza, Z.A. Munir, Fundamental investigations on the spark plasma sintering/synthesis process: I. Effect of dc pulsing on reactivity, Mater. Sci. Eng. A 394 (2005) 132-138.

[15] D. Vjnovic, D. Chicco, H. El, Zenary, Doehlert experimental design applied to optimisation and quantity of a granulation process in high shear mixer, Int. J. Pharm. 145 (1996) 203-213.

[16] D. Gazquez, M. Sanchez-Vinas, M. Gracia Bagur, G. Garcia, Application of Doehlert designs in the optimisation of experimental variables associated with the simultaneous solvent extraction of several metals, J. Anal. At. Spectrom. 13 (1998) 105-108. 